\title{
Dossiê
}

\section{A RELAÇÃO MÃE E FILHO: VICISSITUDES DE UM (DES)ENCONTRO PARA O LAÇO SIMBÓLICO}

do circuito pulsional. Alguns bebês deparam com dificuldades para alcançar o estatuto de Sua Majestade, o Bebê, como dizia Freud. Qual será a situação em casos de trigêmeos? A partir da exposição de um caso clínico, pretendemos discutir as questões do laço simbólico entre mãe e bebê. Descritores: intervenção precoce; laço simbólico; clínica mãe-bebê; função materna.

Cristiani Minga Beltran Fanti Camila Saboia

\section{Introdução}

Quando começa a história de uma criança? Muito provavelmente na história individual de cada um dos pais. É pelo desejo de ter um filho que são reatualizadas as fantasias da própria infância e do tipo de cuidado parental recebido. A função materna que a mãe exerce ocupa um lugar especial para a constituição psíquica do bebê, e cada mãe traz consigo uma história de maternagem singular nos possíveis enlaces com seu filho.

Psicóloga, psicanalista, mestre em Psicologia do Desenvolvimento pela Universidade Federal da Bahia, Salvador,

BA, Brasil.

घ Psicóloga, psicanalista, doutora pela Universidade de Paris 7 , pós-doutorado pelo Instituto de Psicologia da Universidade de São Paulo, São Paulo, SP, Brasil. 
A maternidade, na concepção de Freud, seria a saída feminina para o complexo de Édipo, quando o desejo se articula ao falo, e cujo representante principal seria o filho. A criança ocupa o lugar que Freud (1914/1996b) nomeou de Sua Majestade, o Bebê. Esse é um dos destinos possíveis do complexo de castração na mulher, quando sua demanda é endereçada ao pai, e ela tem seu falo restituído na forma simbólica de um bebê (Faria, 2016).

Jerusalinsky (2012, p. 83) afirma que "a criança existe psiquicamente na mãe muito antes de nascer, muito antes de ser gerada". Antes mesmo de a mulher gerar seu filho, ele já existiria em seu imaginário, e no encontro real poderá corresponder ou não às suas expectativas. Se a história dessa relação se inicia muito antes do nascimento, pode-se dizer que o bebê já nasce com uma história, imerso em um universo simbólico.

Sustentar o desejo de maternagem nos cuidados com um filho pode ser bastante extenuante; e quando se tem gêmeos ou, no presente caso, trigêmeos? Como é possível ao analista intervir para estabelecer ou restabelecer o circuito pulsional da criança no enlace com a mãe, que ocupa a função de Outro primordial e incide na constituição psíquica do bebê?

$\mathrm{Na}$ sequência, serão discutidos o estabelecimento da função materna e o enlace simbólico por meio de um caso clínico - uma criança de 2 anos e 6 meses que apresentou características de fechamento para o Outro.

\section{Uma história de maternagem de trigêmeos}

Recebo Helena no consultório: ela se mostra muito preocupada com um de seus filhos, Gustavo. Ela é mãe de trigêmeos. Eles têm 2 anos e meio, e a queixa de Helena recai inicialmente sobre as dificuldades de assumir a função materna para três crianças: sente-se exausta, apesar de contar com uma rede de apoio familiar - marido, mãe e prima. Resolveu tornar-se mãe após os 40 anos, depois da morte do pai, perda muito sofrida para ela. Segundo Helena, ela buscou preencher essa ausência do pai com o casamento. Logo depois de ter se casado, decidiu que seria mãe e fez uma fertilização.

Vê-se aqui o lugar que os filhos ocuparam no psiquismo de Helena: talvez uma tentativa de obturar o sofrimento da ausência de seu pai, dada a sua morte precoce. Como se a construção de seu desejo materno viesse atrelado a um pedido de arrego que lhe permitisse sentir-se viva apesar da morte de seu pai. Para ela, foi muito sofrido tornar-se mãe de três bebês - sentiu-se desamparada, não sentiu que o marido e a família a apoiavam nos cuidados. Se tornar-se mãe de uma criança já demanda um investimento psíquico, como se dá a qualidade desse investimento quando se tem a demanda de três bebês? Era patente, no psiquismo de Helena, que a maternidade fora algo decidido sem 
uma reflexão sobre como essa decisão implicaria abrir espaço para a entrada dos filhos em sua vida, o que deixava em evidência a sua pouca disponibilidade psíquica para com seus bebês, e a ideia de que seus filhos tivessem a função apenas de consolá-la em seu processo de luto.

Como eu não podia parar de trabalbar, contratei duas babás e uma enfermeira para cuidar. Ficava muito preocupada para conseguir continuar o meu trabalho, pois sendo autônoma não podia parar... Mas ficava pensando: "Nossa! Como é que vai ser com três?".

Essa ausência de disponibilidade psíquica de Helena fez que os cuidados físicos com seus bebês, bem como a execução da rotina, ganhassem um papel e uma dimensão bem mais importante do que de fato o investimento na busca de estabelecer trocas prazerosas com seus bebês, permitindo um verdadeiro encontro entre mãe-bebê. Esse processo da construção da maternidade parece vir carregado de um imenso teor melancólico quando escutamos em seu discurso que todas as dificuldades de desafios da maternidade poderiam ser vivenciadas diferentemente se ela pudesse contar com a presença de seu pai, fantasma esse ainda mais redimensionado pelo fato de ele ser um profissional renomado da primeira infância.

Aspessoas questionam se eu estou farendo certo com eles, principalmente com o Gustavo, que ainda tem dificuldade para falar, que é diferente dos outros dois... Sempre penso: "Nossa! Como queria que meu pai estivesse aqui!". Ele sabia conversar comigo, owvia e orientava, era muito parceiro. Eu compartilhava tudo com ele. Até hoje sonho que ele vem e fala que está tudo bem com o Gustavo.

Além do dificultador da ausência de um desejo genuíno de Helena na escolha da maternidade bem como de sua real disponibilidade psíquica na construção de sua relação com seus bebês, o fato de Gustavo contar ainda com a presença de dois irmãos na disputa da convocação do olhar da mãe, que se mostrava pouco disponível, parece sem dúvida ter facilitado o fracasso de que Gustavo viesse a ocupar o lugar de Sua majestade, o bebê para Helena. 
Gustavo nasceu com o maior peso dos trigêmeos e era muito chorão. Por isso, segundo Helena, era ele quem recebia o leite primeiro desde o berçário e, nas consultas médicas, passava na frente dos demais. Mas seu gênio forte a afastava dele: ela não conseguia acalmá-lo e o entregava para as babás, que faziam uso de tablet, celular e TV, o que pode ter dificultado seu interesse em buscar o contato com os outros a fim de construir um laço social.

Helena conta que, quando Gustavo tinha 1 ano de idade, ela observou uma dificuldade em interessar-se em sustentar a interação com os outros, acompanhado de um isolamento dele em relação ao mundo: não respondia aos chamados; gostava de ficar quieto, mexendo em algum objeto, sem sustentar o olhar. Ficou preocupada, mas o pediatra da época não deu importância e achou que uma mudança nessa situação era apenas questão de tempo, pois quanto ao desenvolvimento físico o menino estava ótimo.

Os principais significantes que se repetiam no discurso de Helena eram: "difícil" (quando falava sobre Gustavo) e "não consigo cuidar de três" (em relação a sua função de mãe). Isso foi ficando cada vez mais evidente pela repetição: "Não consigo sair com os três sozinha e não sei o que fazer com os três". Ao que parece, Gustavo ficou nesse lugar: o difícil, o terceiro, aquele com o qual Helena não sabia como lidar.

Relata que, inúmeras vezes, quando não conseguia acalmá-lo, deixava-o com as babás ou entregava-o para a prima, num tipo de desistência ocasionado pelo seu sentimento de desamparo e de impotência diante da demanda daquele bebê. Essa desistência (ou desinvestimento) da mãe é tratada por Cullere-Crespin (2004), que fala dos estados de sideração para descrever uma espécie de suspensão dos investimentos e das capacidades parentais. A autora afirma que a sideração gela a capacidade do Outro de investir, impedindo os pais de utilizar, nas trocas com os filhos, suas competências.

Embora o estado de sideração possa ser comparado a um estado depressivo, não se trata do mesmo quadro, pois o estado de sideração é vivido como uma falha pela mãe, depois de ela ter investido no filho sem ter resposta - ou seja, a mãe investe, mas, como não é alimentada narcisicamente pelo bebê, passa de forma inconsciente a desinvestir a relação, havendo assim uma ruptura na díade mãe-bebê. Isso vai na contramão da posição defendida pela psicanálise na década de 1970 (Bettelheim, 2001), que afirmava que certas psicopatologias, como o autismo, seriam ocasionadas pela falta de investimento materno - por parte das ditas mães-geladeiras, desprovidas de qualquer afeto pelo bebê.

Assim, quando Helena falava sobre sua experiência de tentar acalmar Gustavo, surgia o sentimento de impotência, de insegurança, pelo não saber, por não conseguir fazer uma hipótese quanto ao que acontecia com ele. Sua percepção sobre as necessidades e demandas do filho muitas vezes a impedia 
de supor um sujeito; restringia-se a acreditar que ele tinha gênio forte.

Quando recebo Gustavo no consultório, surpreendo-me com seu fechamento para com o mundo: fica a maior parte do tempo com o olhar voltado para os objetos, não sustenta o olhar - nem o meu, nem o da mãe -, não expressa nenhuma demanda. Explora os objetos, mas se interessa apenas pelo lápis de cor e pelo papel: desenha círculos no papel e repete o nome da forma (círculo) e o nome das cores. No desenrolar das sessões, aos poucos, consegue solicitar algo para a mãe; às vezes, mostra algum desenho que faz (garatujas de círculos) e responde a alguma pergunta. Parece uma criança triste - não há vitalidade pulsional nas ações. Começa a explorar os objetos, mas em seguida perde o interesse. Algumas vezes, pede para ir embora, puxando a mãe pela mão.

Ele demonstra, inicialmente, algum interesse por personagens de desenho animado; aos poucos, vai ampliando o interesse por brinquedos, mas com pouca procura no olhar, $\mathrm{O}$ que sugeriria um comprometimento na atenção compartilhada (considerada um precursor importante para o estabelecimento de laços sociais); por consequência, um comprometimento na qualidade de brincar interativo e na capacidade do bebê em responder a e sustentar um convite de um brincar a dois. Sendo estes indicadores importantes para se pensar sobre possíveis entraves no processo de subjetivação da criança (Saboia, 2015). 
São visíveis a pobreza simbólica nas brincadeiras de Gustavo e sua falta de reação à saída da mãe da sala. Continua sem convocar o Outro, sem demandar nem sustentar o olhar, sinalizando falhas importantes em seu processo subjetivo, dado o não fechamento do terceiro tempo pulsional do qual nos fala Laznik (2004). Essa autora, ao evocar os três tempos pulsionais de Freud (1915/2013), nos lembra sobre a importância do bebê passar pelo registro do terceiro pulsional, momento no qual "convoca "e "provoca" o Outro na busca de estabelecer trocas prazerosas, como uma espécie de ratificação ou validação do registro precoce do bebê em suas primeiras trocas prazerosas com o Outro primordial.

Quanto ao papel e à função do pai de Gustavo no tratamento, observávamos uma espécie de negação quanto às dificuldades do filho; dizia que não reconhecia a importância do tratamento, embora em nenhum momento se opusesse a ele. Essa conduta do pai parece reforçar o discurso da mãe de sentir-se sozinha e desamparada, abrindo espaço para que ela reforçasse seu fantasma, no qual o único capaz de sustentá-la psiquicamente, no exercício de sua função materna, seria a presença de seu pai morto e não a presença de seu marido, o pai de Gustavo.

A mãe sempre esteve presente nos atendimentos de Gustavo, e este enquadre foi delineado pela queixa inicial de Helena de não conseguir supor um sujeito para seu filho, de não ser capaz de fazer uma leitura das produções dele; ao estar na sessão com o filho, pôde participar dos avanços e das descobertas que este fez, alterando o seu posicionamento com ele. Jerusalinsky (2004) esclarece que o sujeito é efeito da linguagem, antecipado no discurso parental, e a relação da mãe com seu filho é interpretativa e não descritiva; o choro, por exemplo, é um significante que diz se os bebês estão inseridos no campo da linguagem ou não, e é função da mãe interpretar.

Muitos fatores podem ter contribuído para o fechamento de Gustavo em relação ao mundo e ao Outro, por exemplo, o cuidado fragmentado entre tantos adultos, principalmente as babás, que foram substituídas durante os primeiros dois anos. Houve, assim, sofrimento psíquico com as sucessivas interrupções, dificultando o processo subjetivo de Gustavo e as suas potencialidades de advir como sujeito desejante.

Além desses fatores, vale ressaltar o lugar ocupado por Gustavo na fantasia da mãe - o bebê difícil, o que a remetia a sua impotência em ser mãe de três - e o afastamento dela pelo medo de não saber o que fazer para acalmá-lo.

Tudo isso pode ter contribuído para o fechamento de Gustavo em relação ao Outro e para a sua dificuldade em se alienar a este. 
Lacan (1988, p. 199) dirá que a operação da alienação é "a primeira operação essencial em que se funda o sujeito".

Trata-se de uma operação que encontra uma relação íntima com a identificação (Pisetta \& Besset, 2011). O lugar deste Outro que a mãe ocupa ao oferecer significantes, por meio da fala, permite que o bebê se submeta a um ou mais dentre os significantes que lhe são oferecidos, sendo assim capturado num processo de alienação que possibilita constituir-se como um sujeito.

Levanta-se a hipótese de que as falhas da simbolização de Gustavo possam ter influenciado a não alienação; além disso, houve o movimento de desinvestimento de Helena, relegando-o aos cuidados de auxiliares sempre que ele a frustrava.

No decorrer dos atendimentos, Helena pôde, pela organização do seu discurso, ouvir a si mesma e compreender o quanto vários significantes se repetiam, tanto em palavras como em atos, pela percepção de Gustavo como criança difícil.

O principal sofrimento relatado por ela era o distanciamento do filho, por não conseguir acalmá-lo, o que já não é mais assim, pois Gustavo a chama à noite na hora de dormir. Helena está conseguindo conversar com ele; mesmo que ainda não tenha uma resposta tão elaborada, sabe que ele entende, e consegue perceber quem é o sujeito Gustavo.

Em relação ao diagnóstico de Gustavo, ele é colocado em suspensão, em concordância com os trabalhos de Bernardino (2006) e Jerusalinsky (2001). Ambos afirmam que a infância é o momento de constituição da estruturação psíquica; o sujeito pode configurar-se futuramente em uma estrutura definida, mas é preciso percorrer um caminho durante a infância; esse caminho passa por algumas operações psíquicas, e a primeira delas envolve a alienação ao Outro primordial, o exercício das funções materna e paterna para a suposição de um sujeito, de modo que a inscrição simbólica possa avançar. Ainda que tenha um longo caminho a percorrer para a sua subjetividade, Gustavo já está alienado a sua mãe e 
vem progredindo desde o início do tratamento.

As mudanças na posição subjetiva de Gustavo nesse enlace com a mãe aconteceram muito rápido. Em apenas seis meses de tratamento, ele passou a ter momentos nos quais convoca a mãe para brincar, puxa-a pela mão e chama: "Vem, mamãe?", sinalizando a instalação do terceiro tempo pulsional. Gradualmente, ambos vão ficando mais próximos nas sessões; ele aceita as intervenções da mãe com os brinquedos - antes não aceitava e a afastava com a mão.

Ao analista cabe escutar os significantes que se repetem no discurso da mãe e, em uma relação transferencial, fazer intervenções para que esses significantes possam ser ressignificados - quem sabe, promover rupturas neles, abrindo novas possibilidades, novos destinos às pulsões do filho.

$\mathrm{O}$ analista também pode promover uma sustentação da relação entre a mãe e a criança, apostando nesse sujeito, possibilitando outras leituras dele, nomeando suas ações e sua preferência por brincadeiras e brinquedos, e ainda mostrar a alegria das descobertas, como as que tem feito Gustavo nas brincadeiras corporais face a face com a mãe - a descoberta de seu olhar prazeroso nas brincadeiras compartilhadas com ela.

Mas o trabalho não pode estar concluído enquanto o estabelecimento do terceiro tempo do circuito pulsional não estiver completo, enquanto falhas ocorrerem, enquanto a demanda pelo Outro não estiver plenamente estabelecida, não somente entre a criança e a mãe, mas com a criança e os pequenos Outros, seus semelhantes.

Gustavo, agora com 4 anos, já não se encontra num estado de fechamento do tipo autístico: foram feitos muitos avanços na sua interação com a mãe (ambos estão em uma relação prazerosa), e cada vez mais busca os irmãos e consegue brincar com eles.

\section{Discussão}

Com que Outro primordial Gustavo contou para se espelhar nesse início de vida? Talvez um olhar não suficiente para produzir sua alienação, fruto de um desencontro, e, embora ele demonstrasse bastante energia vital, também apresentava irregularidade de humor, tendo mais reações negativas e intensas.

Como já mencionado, parecia não ter alcançado o terceiro tempo do circuito pulsional, que é composto de três tempos: no primeiro, encontra-se a pulsão oral, que Freud denomina de ativa, pois o bebê vai em busca do objeto oral (seio ou mamadeira); no segundo tempo, o bebê apresenta uma capacidade autoerótica, ao chupar a mão ou o dedo, em uma experiência alucinatória de satisfação; finalmente, completando o circuito pulsional, o terceiro, também chamado de satisfação pulsional (Laznik, 2004). 
Nesse terceiro tempo da pulsão, o bebê se oferece como objeto de desejo para o Outro primordial, e existe um prazer que é compartilhado nas interações, quando o bebê visa fisgar o gozo do Outro. Mas no caso dos bebês que ainda não estão no terceiro tempo, ou que não o completaram, esse movimento em direção ao Outro primordial não acontece, ou apresenta falhas, tal qual o relato apresentado em que Gustavo inicialmente não buscava o olhar da mãe e nem compartilhava experiências prazerosas com ela.

A relevância dada à instalação do terceiro tempo pulsional deve-se às pesquisas na clínica da intervenção precoce, que apontam para a manifestação de certas psicopatologias precoces no bebê associadas a uma falha do fechamento deste terceiro tempo, o que, segundo Laznik (2004), provocaria um desarranjo na construção do laço mãe-bebê, pela impossibilidade de o bebê colocar-se como objeto de gozo da mãe, ou seja, de reconhecer-se como responsável por suscitar o prazer no Outro.

Laznik (2004) afirma que pouco importa saber a causa da não instalação do terceiro tempo do circuito pulsional - se provém de certa dificuldade constitutiva da criança, que não procura o Outro ativamente, ou de uma falta de resposta do Outro primordial (ou daquele que ocupa esse lugar). Segundo a autora, há falha nos dois casos, e pode-se pensar que houve um desencontro que impediu o fechamento do circuito pulsional e, com isso, comprometeu a posição de alienação do bebê em relação ao Outro, posição essa fundamental para o seu processo de advir como sujeito.

Nesse sentido, a autora salienta:

esse olhar é o que funda a possibilidade mesma da constituição da imagem do corpo e da relação com o semelhante... o não olhar entre uma criança e sua mãe (sobretudo quando ela não se apercebe disso) assinala o perigo de problemas precoces na relação com o Outro. (Laznik, 2004, p. 25)

Esse não olhar é considerado por Laznik como um sinal de risco para a instalação do autismo. A autora alerta 
para o perigo da não constituição do estádio do espelho ou de uma constituição falha, caso o olhar entre mãe e filho não se instale.

Por meio do conceito de estádio do espelho, Lacan (1949/1998a) explica como acontece a constituição do sujeito. Com esse conceito, o autor se refere não ao espelho no sentido concreto, mas a uma perspectiva na qual o olhar do Outro devolve à criança uma ilusão de completude (De Césaris, 2016).

Lacan exemplifica, nessa cena, a reação da criança diante de sua imagem no espelho: num primeiro momento, ela é indiferente à presença do espelho; mais tarde, porém, tem uma reação de júbilo ao ver sua imagem refletida.

Faria (2016) esclarece que essa transformação exige muito mais do que a presença de um espelho, a presença daquele que segura a criança e nomeia a imagem projetada no espelho como sendo a dela: é necessário alguém que dê suporte à linguagem e ao significante.

É a esse Outro, tão relevante para a constituição do Eu, que a criança necessita alienar-se - um processo de alienação ao campo do Outro e ao significante que dará suporte à imagem. Trata-se de uma alienação necessária e estruturante, que transforma a fragmentação corporal em unidade ilusória de si.

Nesse processo de alienação ocorre um assujeitamento aos significantes que o sujeito recolhe do Outro, que tem na função materna o suporte concreto, conforme aponta Faria (2016).

A criança, no entanto, ao se virar e olhar para a mãe, diante do espelho, tem em seu gesto um apelo de confirmação e reconhece, nesse apelo, uma evidência que não esgota a alienação somente à imagem no espelho. Lacan vai dizer que ela não é, portanto, meramente cativa dessa imagem que a constitui (Faria, 2016). A criança pode encontrar um espaço entre os significantes que vão constituir seu desejo, sem submeter-se plenamente ao Outro.

Nesse desencontro, o fechamento do terceiro tempo da pulsão para a alienação ao Outro, Laznik (2004) salienta que é preciso incluir a voz e o olhar - dois

288 Estilos clin., São Paulo, v. 23, n. 2, maio/ago. 2018, 279-295. 
elementos pulsionais que contribuem para a constituição da vivência de um corpo unificado -, especialmente nas pesquisas sobre o autismo, para que o bebê se torne um sujeito de desejo. É a mãe enquanto Outro primordial que, por meio de sua voz e de seu olhar, vai encantar esse pequeno sujeito, em um processo de alienação e também de suposição de um sujeito nesse bebê.

Nessa relação, é interessante pensar no fato de Gustavo contar com mais dois irmãos gêmeos, e que estes podem ter contribuído para o desenvolvimento de sua imagem, numa identificação à imagem do semelhante.

Helena acreditava que Gustavo necessitava se diferenciar dos irmãos, através de certo negativismo em relação a eles, demonstrando sempre um gosto diferente do deles.

O suposto negativismo em relação aos irmãos pode ser interpretado como uma tentativa de se diferenciar deles, algo muito bem-vindo, pois na constituição de um sujeito são necessárias tanto a alienação ao Outro, conforme já discutido, como também a separação em relação a ele, como relatam Kupfer, Faria e Keiko (2007) acerca do trabalho com crianças que estão no discurso psicótico, nas quais há falhas na operação de separação. É preciso alienar-se para poder separar-se, na busca de uma diferenciação.

Muito embora esse processo de separação ocorra usualmente em relação ao Outro primordial (normalmente a mãe), para Gustavo, a convivência mais próxima com os irmãos, na qualidade de pequenos Outros, pode ter facilitado sua alienação a estes e sua tentativa de se diferenciar deles.

Faria (2016) esclarece ainda que o falo é o terceiro elemento na relação mãe-criança. Lacan (1949/1998b) acrescenta uma nova perspectiva, na qual a função da mãe está ligada ao lugar do Outro primordial, de suporte primeiro do campo da linguagem para a criança. A criança ocupará um lugar fálico, um lugar no desejo da mãe, tornando possível um enlace - fundamental para a mãe e para a constituição psíquica da própria criança.

Como Gustavo ocupou esse lugar fálico para Helena? Lacan (1986) nos faz pensar sobre o valor da transmissão de uma geração para a outra, que, segundo o autor, não é da ordem da satisfação das necessidades, mas, sim, da constituição subjetiva, implicando a relação com um desejo que não seja anônimo.

Que desejo é esse de Helena, tornar-se mãe por meio de inseminação artificial, sem tentar o método tradicional de concepção? Como esses filhos se vinculam ao desejo em relação ao marido?

Tais perguntas surgem e corroboram a importância de escutar os pais nas entrevistas iniciais e de manter as intervenções com a criança concomitantemente a essa escuta, para que não se percam os benefícios da neuroplasticidade cerebral, trabalhando com a vitalidade psíquica do bebê na direção da instalação do terceiro tempo pulsional. 
Ao escutar Helena em sua fantasmática acerca da maternidade, permite-se que ela elabore a ausência de seu pai, a escolha de ser mãe e como os filhos podem ocupar um lugar em sua vida mental que não seja o de tamponar a saudade do pai.

O objetivo da inclusão da posição parental no tratamento da criança não se deve à necessidade de orientá-los, segundo uma perspectiva pedagógica ou comportamental, mas de ajudá- los a redimensionar os problemas do filho, para poderem situar-se em relação aos próprios problemas, como abordado nos trabalhos de Françoise Dolto (1971/2004) e Maud Mannoni (1971/2004).

A escuta à mãe é também necessária por ela ocupar o lugar de Outro primordial e apresentar dificuldades para exercer a função materna, colocando em risco a estruturação psíquica do bebê.

Essa intervenção, portanto, assemelhou-se a uma tentativa de proporcionar primeiramente um holding para a mãe, para que ela pudesse vir a potencializar-se narcisicamente na sua própria capacidade de exercer sua função materna para com esse bebê. Assim, Helena teve a oportunidade de vivenciar, na experiência transferencial com a analista, uma relação especular, para que ela pudesse novamente investir libidinalmente em seu bebê. É nesse sentido que dizemos que a clínica da intervenção precoce seria, de fato, baseada na ideia de ser a clínica do holding do holding.
Lacan (1984/2008) desenvolve essa ideia ao falar do complexo de intrusão, encarnado no irmão que chega como um intruso na relação com o Outro primordial, tirando o privilégio da amamentação e trazendo a vivência da perda do objeto primordial e a experiência do desejo e do corpo próprios - não é mais um corpo devido ao Outro, como nos lembra Bernardino (2001). É por isso que o irmão pode ser ao mesmo tempo um objeto odiado a ser destruído, e nesse contexto surge a agressividade, e um objeto de identificação, enquanto assegura um Eu próprio pela diferença de posições.

Podemos pensar, à luz do que nos trazem Bernardino (2001) e Lacan (1984/2008), que o complexo de intrusão, deflagrado pela participação dos irmãos de Gustavo, pode ter colaborado em sua constituição subjetiva, ao direcionar seu desejo para esse Outro primordial, desencadeando, segundo a leitura da mãe, ciúme.

Entretanto, no caso de irmãos gêmeos, Gueller (2018) aponta que os afetos como inveja, ciúmes e ódio não têm lugar inicialmente nos gêmeos, já que eles se percebem e se pensam como Um. Seria, portanto, necessário um trabalho de diferenciação psíquica entre estes para que avançassem em termos subjetivos.

É interessante a visão de Helena de que seu filho já estaria demonstrando ciúme dos irmãos, mas o ciúme requer uma organização psíquica mais elaborada. $\mathrm{O}$ que de fato 
se pode supor é que Gustavo estivesse ainda no registro da agressividade e do ódio para com os irmãos (mordia, empurrava e gritava), o que denotava uma primeira separação desses pequenos Outros.

Na constituição psíquica do Eu da criança, é preciso ocorrer uma diferenciação entre o Eu e o Não Eu, e é na alteridade que o sujeito pode começar a mostrar que ele não é como o Outro, que ele não é o espelhamento do Outro, que ele tem seu desejo.

Gustavo, pelos seus nãos, demonstra que recusa a intrusão dos irmãos em seu psiquismo, processo esse importante para a formação do Eu - diferenciar-se do Não Eu, o que está em concordância com o apontado por Gueller e Morgenstern (2018) quando inicialmente os gêmeos e trigêmeos podem ainda não estar diferenciados um do outro.

Lacan (1966/1998) aborda a constituição do Eu por meio do tratamento do Outro, quando diz que é necessário operar um estranhamento, uma separação entre a criança e seu Outro. Os irmãos, como visto, também podem ter configurado o Outro nesse espelhamento inicial, e aos poucos Gustavo vai diferenciar-se deles, à medida que sua constituição do Eu avançar.

Tais hipóteses dentro do tratamento são bem mais positivas quando comparadas às dificuldades de alienação ao Outro primordial e à não instalação do circuito pulsional, pois indicam que há possibilidade de alienação, uma vez que existe um desconforto quanto a esses semelhantes, esse duplo que são os irmãos, e que o Outro semelhante já é também uma possível alienação. O complexo de intrusão com os irmãos e a agressividade em relação a eles, inclusive por serem trigêmeos e estarem muito próximos, podem ter colaborado para dificultar uma possível relação fusional e de assujeitamento com a mãe.

A partir da noção de bebê competente e participativo (Saboia, 2006) no processo de construção do enlace com o Outro primordial, o trabalho na clínica com bebês reflete acerca de como é possível ao analista intervir no (des)encontro entre mãe e filho, visando ao estabelecimento ou ao restabelecimento do circuito 
pulsional, o que implica oferecer as condições necessárias para que mãe e bebê possam tentar (re)inscrever uma nova história e uma narratividade no que diz respeito ao encontro e às trocas prazerosas entre eles (Golse, 2004).

A aposta de que aconteçam trocas prazerosas entre mãe e bebê, na clínica da intervenção precoce, nos faz recordar o que Freud (1914/1996b) sugere sobre o amor parental: este nada mais é do que a tentativa de resgatar o próprio narcisismo infantil perdido; assim, os pais colocam o filho no lugar de Sua Majestade, o Bebê, no lugar de objetos narcísicos a serem investidos libidinalmente. O bebê teria, portanto, a função reparadora de suturar no psiquismo dos pais as feridas narcísicas deles.

A relação entre mãe e filho, porém, não é um processo garantido por condições naturais: como ressaltam Kupfer et al. (2009), depende do estabelecimento de um laço simbólico, que é construído gradativamente por meio das trocas mãe-bebê, regidas pelos investimentos narcísicos e pulsionais.

\section{Conclusão}

Através da escuta de Helena pela psicanalista, sobre a pré-história e a história de Gustavo, foi possível captar no discurso significantes que se repetiam e que, por estarem excluídos de simbolização na consciência, continuavam a se repetir em atuações.

Freud (1914/1996a) diz que, devido à impossibilidade de recordar, o paciente repete em atuações o que está excluído de sua elaboração na consciência. Analisando o conceito de repetição, Lacan (1985) acrescenta que ela nunca é idêntica: há sempre um elemento novo, pois nunca se repete da mesma maneira.

Em um trabalho de análise, o sujeito pode ressignificar significantes-mestres que regem de forma dura seu campo subjetivo, que se repetem por falhas na representação simbólica. Assim, cabe ao analista intervir para que a mãe consiga fazer as elaborações simbólicas desses significantes, que se traduzem em atuações na relação com o bebê e que, na análise, dão início a outras cadeias de significantes.

Essas intervenções com a mãe podem ter um caráter preventivo, para que as mudanças conquistadas no que se refere à reinstalação ou à instalação do circuito pulsional no bebê possam ter continuidade após o término do tratamento. Lembrando aqui que a psicanálise pensa a prevenção não como uma tentativa de suprimir os sintomas, sendo estes constitutivos ao sujeito, mas como uma possibilidade de oferecer uma escuta atenta aos sinais de sofrimento do bebê.

Considera-se que a intervenção precoce pela psicanálise é o caminho que pode impedir que riscos psíquicos graves se instale no bebê, tal como o autismo, tanto por envolver a escuta 
do Outro primordial quanto por realizar intervenções para que aconteça o enlace simbólico com o bebê.

Uma nova concepção sobre o trabalho com a clínica das psicopatologias precoces oferece diferentes perspectivas sem apelar ao binômio causa e consequência, modelo esse reducionista, culpabilizante e insuficiente para o trabalho com a intervenção precoce.

Ainda que ocorram vicissitudes de um desencontro entre mãe e bebê, é possível trilhar outros caminhos e novos olhares, ressignificar significantes, reescrever uma nova historia entre mãe e filho, pois seria através de reconstrução que poderíamos oferecer as condições necessárias para que o bebê possa vir a se enlaçar com o Outro, garantindo, assim, seu acesso ao campo da linguagem e seu estatuto de sujeito desejante.

MOTHER-BABY RELATIONSHIP: VICISSITUDES OF THE (DIS)ENCOUNTER FOR SYMBOLIC TIES

\begin{abstract}
The clinic of child early intervention invites us to think about the mother's function as part of the construction of the ties with the Primordial Other and about how the analyst can intervene in the (dis)encounter between mother and child, aiming at the establishment or the re-establishment of the pulsion. Some babies are struggling to reach the status of His Majesty, the Baby, as Frend would say. How would it be in cases of triplets? Through the presentation of a clinical case, we intend to discuss the issues of the symbolic ties between mother and baby.
\end{abstract}

Index terms: early intervention; symbolic ties; mother-baby clinic; mother's function.

LA REL ACIÓN MADRE-BEBÉ: VTCISITUDES DE (DES)ENCUENTRO PARA EL LAZO SIMBÓLICO

\title{
RESUMEN
}

La clínica de la intervención precoz nos convoca a reflexionar sobre la función materna en el proceso de construcción del enlace con el Otro primordial y de cómo es posible la intervención del analista en el (des)encuentro madre e bijo, con el fin de establecer o de restablecer el circuito pulsional. Algunos bebés encuentran dificultades para alcanzar el estatuto de "Su Majestad, el Bebé", como decía Freud. ¿Cuál será la situación en caso de trillizos? A partir de la exposición de un caso clínico, pretendemos discutir las cuestiones del lazo simbólico entre madre y bebé.

Palabras clave: intervención precoz; lazo simbólico; clinica madre-bebé; función materna.

\section{REFERÊNCIAS}

Bernardino, L. M. F. (2001). O ciúme na relação entre irmãos, a partir de um caso de gagueira. In Colóquio Franco-Brasileiro Modernité des Liens Fraternels et Conjugaux: Fraternité ou Communautarisme, 2001, Paris. Recuperado de http://www.ip.usp.br/laboratorios/lvida/ coloquios/ociume.htm 
Bernardino, L. M. F. (Org.). (2006). O que a psicanálise pode ensinar sobre a criança, sujeito em constituição. São Paulo, SP: Escuta.

Bettelheim, B. (2001). La fortaleza vacia: autismo infantil y el nacimiento del yo (A. Abad, trad.). Barcelona: Paidós.

Cullere-Crespin, G. (2004). Os sinais de sofrimento psíquico. In G. Cullere-Crespin, A clínica precoce: o nascimento do humano (C. M. Fernandes et al., trads., pp. 47-69). São Paulo, SP: Casa do Psicólogo.

De Césaris, D. M. C. (2016). A imagem corporal especular no sujeito em constituição, de Freud a Lacan. São Paulo, SP: Escuta.

Dolto, F. (2004). Prefácio. In M. Mannoni, A primeira entrevista em psicanálise (R. C. de Lacerda, trad., pp. 7-33). Rio de Janeiro, RJ: Elsevier. (Trabalho original publicado em 1971).

Faria, M. R. (2016). Introdução à psicanálise de crianças: o lugar dos pais. São Paulo, SP: Toro.

Freud, S. (1996a). Recordar, repetir e elaborar. In S. Freud, Edição standard brasileira das obras psicológicas completas de Sigmund Freud (J. Salomão, trad., Vol. 12, pp. 163-171). Rio de Janeiro, RJ: Imago. (Trabalho original publicado em 1914)

Freud, S. (1996b). Sobre o narcisismo: uma introdução. In S. Freud, Edição standard brasileira das obras psicológicas completas de Sigmund Freud (J. Salomão, trad., Vol. 14, pp. 77-108). Rio de Janeiro, RJ: Imago. (Trabalho original publicado em 1914)

Freud, S. (2013). Pulsöes e seus destinos. Belo Horizonte, MG: Autêntica. (Trabalho original publicado em 1915)

Golse, B. (2004). L'être bébé. Paris: PUF.

Gueller, A. J. S. (2018). É o gêmeo um irmão? Reflexões sobre as diferenças entre as relações fraternas e as relaçôes gemelares. In $V$ Colóquio de Psicanálise com Crianças: a criança e o mal-estar contemporâneo, 2018, São Paulo, SP. São Paulo, SP: Sedes Sapientiae. Recuperado de http:// www.sedes.org.br/Departamentos/Psicanalise_crianca/Vcoloquio/trabalhos.html

Gueller, A. J. S. \& Morgenstern, A. (2018). Atendimento psicanalitico de gêmeos. São Paulo, SP: Zagadoni.

Jerusalinsky, A. (2001). Por que as estruturas psicopatológicas na infância são não decididas? Trabalho apresentado em seminário no Instituto de Psicologia da Universidade de São Paulo, São Paulo. Jerusalinsky, A. (2004). Desenvolvimento e psicanálise. In A. Jerusalinsky, Psicanálise e desenvolvimento infantil: um enfoque transdisciplinar (D. M. Lichtenstein, trad., 3a ed., pp. 23-31). Porto Alegre, RS: Artes e Ofícios.

Jerusalinsky, A. (2007). A educação é terapêutica? Sobre três jogos constituintes do sujeito (parte 1). In A. Jerusalinsky, Psicanálise e desenvolvimento infantil (pp. 155-160). Porto Alegre, RS: Artes e Ofícios.

Jerusalinsky, A. (2012). Aspectos constitucionais do bebê e sua influência na relação Mãe-Filho. In A. Jerusalinsky, Psicanálise do autismo (p. 83). São Paulo, SP: Instituto Langage.

Kupfer, M. C. M., Faria, C., \& Keiko, C. (2007). O tratamento institucional do Outro na psicose infantil e no autismo. Arquivos Brasileiros de Psicologia, 59(2), 156-166.

294 Estilos clin., São Paulo, v. 23, n. 2, maio/ago. 2018, 279-295. 
Kupfer, M. C. M., Jerusalinsky, A., Bernardino, L. M. F., Wanderley, D., Rocha, P. S. F., Molina, S. E., .. L Lerner, R. (2009). Valor preditivo de indicadores clínicos de risco para o desenvolvimento infantil: um estudo a partir da teoria psicanalítica. Latin-American Journal of Fundamental Psychopathology, 6(1), 48-68.

Lacan, J. (1985). O seminário, livro 11: os quatro conceitos fundamentais da psicanálise, 1964 (M. D. Magno, trad.). Rio de Janeiro, RJ: Jorge Zahar.

Lacan, J. (1986). Duas notas sobre a criança. Ornicar? Revista do Campo Freudiano, 37, 13-14.

Lacan, J. (1988). O seminário, livro 11: os quatro conceitos da psicanálise. Rio de Janeiro: Jorge Zahar.

Lacan, J. (1998). De uma questáo preliminar a todo tratamento possível da psicose. In J. Lacan, Escritos (V. Ribeiro, trad., pp. 537-590). Rio de Janeiro, RJ: Jorge Zahar. (Trabalho original publicado em 1966)

Lacan, J. (1998a). O estádio do espelho como formador da função do Eu. In J. Lacan, Escritos (V. Ribeiro, trad., pp. 96-103). Rio de Janeiro, RJ: Jorge Zahar. (Trabalho original publicado em 1949)

Lacan, J. (1998b). A instância da letra no inconsciente ou a razão desde Freud. In J. Lacan, Escritos (V. Ribeiro, trad., pp. 496-533). Rio de Janeiro: Jorge Zahar. (Trabalho original publicado em 1949)

Lacan, J. (2008). Os complexos familiares (M. A. C. Jorge \& P. M. da Silveira Júnior, trads.). São Paulo, SP: Jorge Zahar. (Trabalho original publicado em 1984)

Laznik, M.-C. (2004). A voz da sereia: o autismo e os impasses na constituição do sujeito (C. F. Rohenkol, trad.). Salvador, BA: Ágalma.

Mannoni, M. (2004). A primeira entrevista em psicanálise (R. C. de Lacerda, trad.). Rio de Janeiro: Elsevier. (Trabalho original publicado em 1971)

Pisetta, M. A. M. \& Besset, V. L. (2011). Alienação e separação: elementos para discussão de um caso clínico. Psicologia em Estudo, 16(2), 317-324.

Saboia, C. (2006). O papel do bebê no processo de acesso à subjetivação. Estilos da Clínica, 11(21), 186-195. DOI: 10.11606/issn.1981-1624.v11i21p186-195

Saboia, C. (2015). O brincar precoce do bebê como indicador de riscos de sofrimento psíquico. Estilos da Clínica, 20(2), 181-193. DOI: 10.11606/issn.1981-1624.v20i2p181-193

cristiani.beltran@gmail.com Rua Coronel Pedro de Oliveira, 580, sala 33 18030-220 - Sorocaba - SP - Brasil.

camila_saboia@hotmail.com

Avenida Rouxinol, 84, sala 86 04516-000 - São Paulo - SP - Brasil. 